\title{
Mechanical Behavior of Unsaturated Soils Subjected to Impact Loading
}

\author{
Xianqi Xie,, ${ }^{1,2}$ Yingkang Yao, ${ }^{1,2}$ Jun Liu, ${ }^{2}$ Peining Li, ${ }^{1}$ and Gui Yang ${ }^{2}$ \\ ${ }^{1}$ Wuhan Municipal Construction Group Co. Ltd., Wuhan 430023, China \\ ${ }^{2}$ College of Civil and Transportation Engineering, Hohai University, Nanjing 210098, China \\ Correspondence should be addressed to Gui Yang; ygheitu@163.com
}

Received 24 May 2015; Revised 12 August 2015; Accepted 31 August 2015

Academic Editor: Georges Kouroussis

Copyright (c) 2016 Xianqi Xie et al. This is an open access article distributed under the Creative Commons Attribution License, which permits unrestricted use, distribution, and reproduction in any medium, provided the original work is properly cited.

\begin{abstract}
This paper presents an experimental study on unsaturated soils. A designed test setup was used and the impact loading was applied with a drop hammer. The experimental results show that the soil properties, including water content, density, void ratio, and saturation, changed because of impact loading, and these variations of the soil properties affected the matrix suctions of the unsaturated soils. The impact hole depth increased with the increasing impact energy and gradually reached a critical value. The dynamic stress in soil increased with the increased impact loading. The results obtained in this work can be applied to optimize the effective reinforcement region of soils in the dynamic compaction construction.
\end{abstract}

\section{Introduction}

The mechanical characteristics of soils subjected to impact loading play important roles in engineering practice, such as the dynamic consolidation method and blasting compaction. However, changes in the original soil structure under impact loading may lead to extremely complicated soil mechanical behavior [1]. The current research methods for the mechanical characteristics of soils subjected to impact loading mainly include consolidation experiments and numerical simulations.

Consolidation experiments are used to enhance the bearing capacity of soils by changing the physical properties of soils and loading approaches [2]. In the regime of impact loading, soil structures significantly affect the dynamic behavior of soils. Moreover, the water content and density of the soil also influence the soil dynamic behavior. Typically, the parameters influencing the behavior of soil subjected to impact loading are investigated individually rather than in certain combinations $[3,4]$. Dynamic consolidation experiments are mainly conducted with press machines or vertical pendulums by applying impact loading with different frequencies, eccentricities, and intervals of loading times [58]. These techniques have been used to study the deformation characteristics of saturated soils [9]. However, the loading frequencies of pressure machines and vertical pendulums were too low, and the influences of the stress wave propagation, reflection at the boundaries, and superposition are usually ignored. Compared to saturated soils, the dynamic behavior of unsaturated soils is much more complicated. This is because the presence of gas in unsaturated soils results in the discontinuity of soil structures, variation of saturation, flow of gas under impact loading, and so forth. These characteristics impede the research from obtaining more realistic relationships between unsaturated soil behavior under impact loading and the impact energies. Therefore, the assumption of continuity in soils is still employed to study unsaturated soils. For example, Krümmelbein et al. [10] compared the deformation characteristics of unsaturated soils under static and dynamic stress and proposed a function of gas pores to evaluate the deformation. Omidvar et al. [11] observed the deformations of gas pores of unsaturated soils under impact loading, found that the compression in soil made pores disperse toward the surroundings, which significantly affected the soil deformation, and estimated the affected regions by impact loads. Although many research efforts have been undertaken in this field, the mechanical behavior of unsaturated soils under impact loading can be 


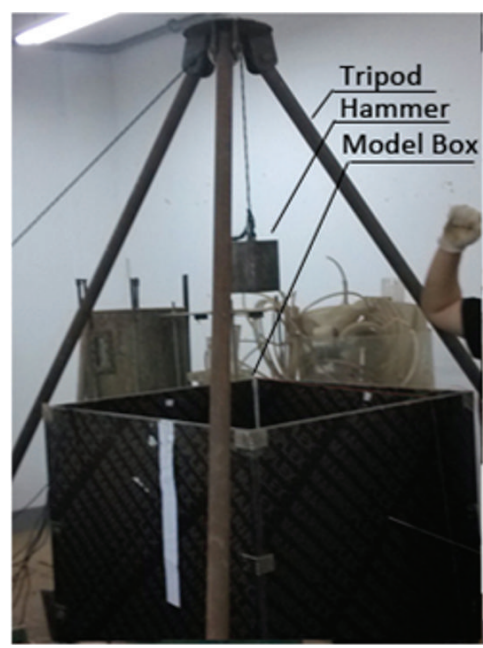

(a)

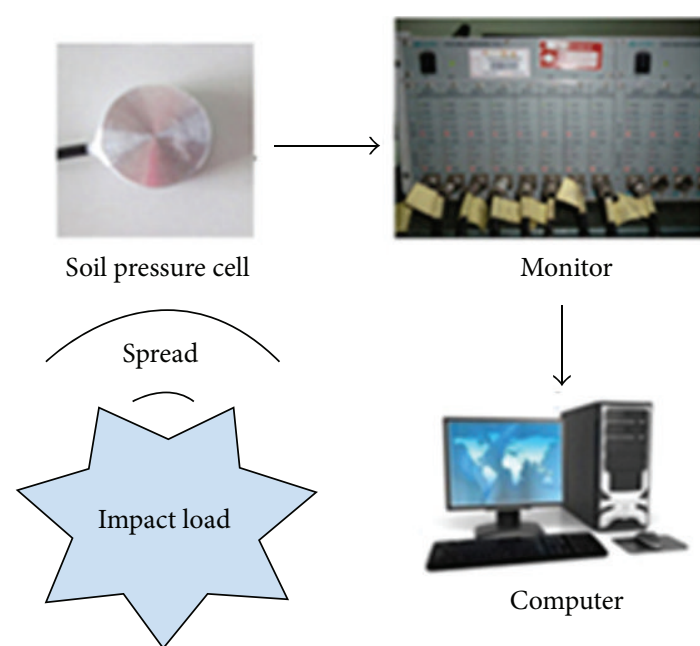

(b)

FIGURE 1: Experimental apparatus: (a) setup; (b) instrumentation.

determined only qualitatively due to the many factors and great variation of soil properties [12].

Numerical simulations have more advantages in terms of changing the soil models and loading approaches. For instance, the time history of dynamic stress and the density of soils can be demonstrated with Ls-Dyna [13]. Holloman et al. [14] proposed a particle based simulation method to model the acceleration of sands based on the explosive and its impact with the test structure, and this method was able to predict both the impulse and pressure transferred. However, numerical simulations are difficult to correctly model the microstructure of soils, and it is difficult to accurately determine the material parameters of constitutive models, thus limiting the role of numerical simulations in studying the mechanical behavior of unsaturated soils under impact loading.

In this paper, considering the characteristics of the discontinuous pores in unsaturated soils, the mechanical behavior of unsaturated soils under impact loading was experimentally investigated with a designed test setup in which a drop hammer was used to apply impact loads. The variations in the deformation and the stress of unsaturated soils were investigated in terms of soil structures and impact loading methods. The dynamic consolidation procedure is demonstrated by changes in saturation, water content, density, and compressibility before and after the impact loading.

\section{Experimental Methods}

2.1. Test Setup. The test setup consisted of a tripod, a drop hammer, and a wooden model box, as shown in Figure 1. The tripod and hammer were used to apply different impact loads. Clay was dried, crushed, sieved, and mixed with different amounts of water to produce unsaturated soil samples with different water contents. Then, the samples were placed in the box with a series of earth pressure boxes to measure the stress distribution inside.
TABLE 1: The parameters of the drop hammer.

\begin{tabular}{lccc}
\hline Mass $/ \mathrm{kg}$ & Weight $/ \mathrm{N}$ & Diameter $/ \mathrm{mm}$ & Height $/ \mathrm{mm}$ \\
\hline 16.8 & 164.6 & 135 & 145 \\
\hline
\end{tabular}

The drop hammer is a cylinder with a diameter of $135 \mathrm{~mm}$ and a weight of $16.8 \mathrm{~kg}$. Different impact energies were achieved by adopting different drop heights, as shown in Table 1.

Because the diameter of the hammer was $13.5 \mathrm{~cm}$, it was estimated that the diameters of the holes due to impact loading would be $15 \mathrm{~cm}$ to $20 \mathrm{~cm}$. To avoid the influence of size effects, it was estimated that the affected regions of the soils under impact loading would be $30 \mathrm{~cm}$ to $40 \mathrm{~cm}$. Considering the estimate error and the operation space, the horizontal dimensions of the model box were eventually chosen as $80 \mathrm{~cm}$ by $80 \mathrm{~cm}$ to provide an adequate space. The model box was made of wooden plates with a thickness of $2 \mathrm{~cm}$. To prevent any failure caused by soil pressure, the box was strengthened by nailing steel angles at the four corners.

The model box was $1.2 \mathrm{~m}$ high with a $10 \mathrm{~cm}$ thick layer of drainage sand placed at the bottom, as shown in Figure 2(a). The dynamic soil stress decreases along the soil depth. Therefore, to measure the dynamic soil stress at the bottom of the model box, the spacing of earth pressure boxes at the lower part of the model box was smaller than that at the upper part. Figure 2 shows the layout of earth pressure boxes in the vertical and horizontal directions when the drop height was $0.8 \mathrm{~m}$.

The formula of effective reinforcement depth due to dynamic consolidation in the Chinese national code for the design of a building foundation [15] was used to estimate the depths of soil samples in the test. Table 2 lists the effective reinforcement depth under different impact energies. 
TABLE 2: Estimates of effective reinforcement depths under different impact energies.

\begin{tabular}{lccc}
\hline Drop height $/ \mathrm{m}$ & Impact energy/N·m & Effective reinforcement depth/m & Selected soil sample depth/m \\
\hline 0.4 & 65.84 & $0.25 \sim 0.27$ & 0.5 \\
0.6 & 98.80 & $0.40 \sim 0.50$ & 0.6 \\
0.8 & 131.68 & $0.53 \sim 0.66$ & 0.7 \\
1.0 & 164.60 & $0.66 \sim 0.82$ & 0.8 \\
\hline
\end{tabular}

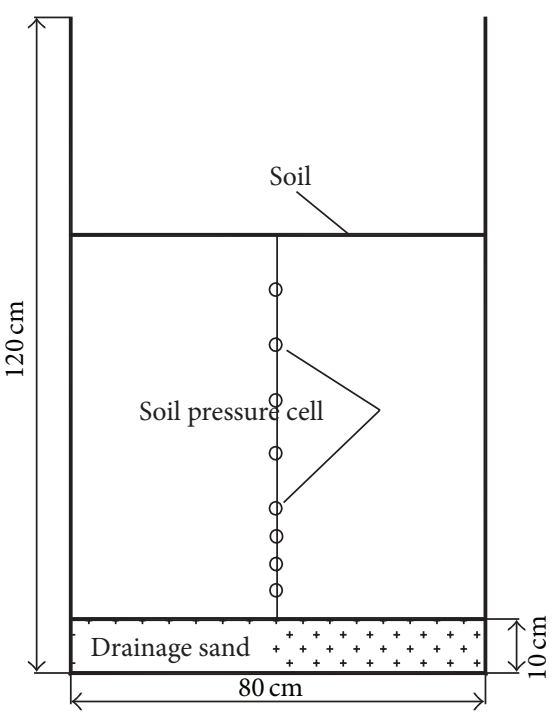

(a)

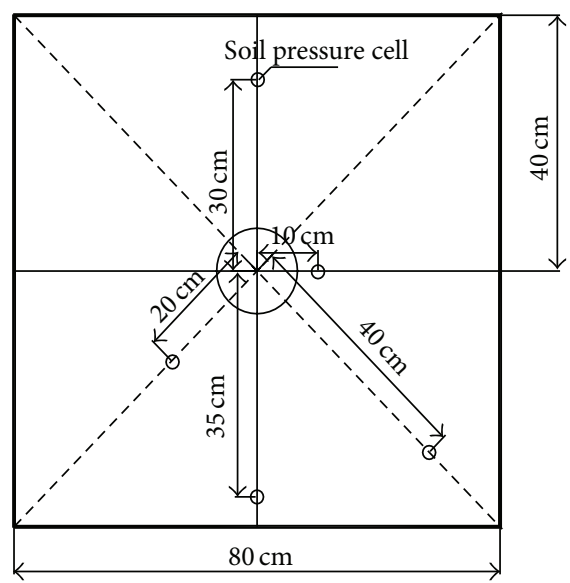

(b)

FIGURE 2: Layout of earth pressure boxes at a drop height of $0.8 \mathrm{~m}$ : (a) in the vertical direction; (b) in the horizontal direction.

\subsection{Test Procedures}

(1) A $10 \mathrm{~cm}$ thick layer of dry sand was placed at the bottom of the model box and covered by a layer of geotextile to prevent the mixture of sand and silty clay.

(2) The soil samples were filled in the model box layer by layer. Meanwhile, the earth pressure boxes were placed at a certain soil layer. To measure the stresses in one direction, the clear distance between earth pressure boxes was kept between 2 and 5 times the diameter of the earth pressure boxes to minimize the interruptions of the earth pressure boxes on each other.

(3) When the soil samples were filled to the specified depth, the tripod was set up and leveled to ensure that the drop hammer coincided with the center of the soil sample.

The drop height of the hammer was set to $0.4 \mathrm{~m}, 0.6 \mathrm{~m}$, $0.8 \mathrm{~m}$, and $1.0 \mathrm{~m}$, and the corresponding four sets of impact energies are listed in Table 3; these were employed to investigate the relationships of the deformation of impacted soils and the impact energies. According to the soil properties and the thicknesses of the soil samples, the impact loading for one impact energy was between 10 and 13 .
TABLE 3: Drop heights and impact energies.

\begin{tabular}{lcc}
\hline Set number & Drop height $h(\mathrm{~m})$ & Impact energy $(\mathrm{N} \cdot \mathrm{m})$ \\
\hline I & 0.4 & 65.84 \\
II & 0.6 & 98.80 \\
III & 0.8 & 131.68 \\
IV & 1.0 & 164.60 \\
\hline
\end{tabular}

Note: impact energy $E=m g h ; m$ : mass of the drop hammer; $h$ : drop height; $g=9.8 \mathrm{~N} / \mathrm{kg}$.

\section{Experimental Results}

3.1. Variation of Soil Properties before and after Impact Loading. The dynamic behavior of unsaturated soils was studied by comparing the water content, density, saturation, and so forth of the soil samples before and after the impact loading.

3.1.1. Variation of Water Content. The impact loading changed the structure of soil particles and hence the distribution of pore water, resulting in variation of the water content. Essentially, when the water content is low, the soil particles are loosely and randomly distributed. However, with increasing water content, the soil is gradually compacted, and the soil particles are more directionally distributed. For each drop height, the water content of the soils at different depths below the bottom of the impacted holes was determined using a dyeing method before and after the impact loading. The water 
TABLE 4: Water content of soils below the bottom of the impacted holes.

\begin{tabular}{|c|c|c|c|c|c|c|c|c|}
\hline \multirow{2}{*}{ Label } & \multicolumn{2}{|c|}{$h=0.4 \mathrm{~m}$} & \multicolumn{2}{|c|}{$h=0.6 \mathrm{~m}$} & \multicolumn{2}{|c|}{$h=0.8 \mathrm{~m}$} & \multicolumn{2}{|c|}{$h=1.0 \mathrm{~m}$} \\
\hline & Before impact & After impact & Before impact & After impact & Before impact & After impact & Before impact & After impact \\
\hline I & $19.85 \%$ & $18.35 \%$ & $20.09 \%$ & $18.50 \%$ & $19.81 \%$ & $18.43 \%$ & $19.46 \%$ & $18.49 \%$ \\
\hline II & $20.06 \%$ & $18.22 \%$ & $19.49 \%$ & $18.36 \%$ & $20.54 \%$ & $18.87 \%$ & $20.00 \%$ & $18.04 \%$ \\
\hline III & $19.47 \%$ & $18.87 \%$ & $19.61 \%$ & $18.67 \%$ & $19.50 \%$ & $18.13 \%$ & $19.46 \%$ & $18.81 \%$ \\
\hline IV & $20.10 \%$ & $18.63 \%$ & $19.96 \%$ & $18.23 \%$ & $18.45 \%$ & $18.11 \%$ & $19.54 \%$ & $18.36 \%$ \\
\hline Average & $19.87 \%$ & $18.52 \%$ & $19.79 \%$ & $18.44 \%$ & $19.58 \%$ & $18.39 \%$ & $19.61 \%$ & $18.43 \%$ \\
\hline
\end{tabular}

TABLE 5: Density of soils below the bottom of the impacted holes.

\begin{tabular}{lcccccccc}
\hline \multirow{2}{*}{ Label } & \multicolumn{2}{c}{$h=0.4 \mathrm{~m}$} & \multicolumn{2}{c}{$h=0.6 \mathrm{~m}$} & \multicolumn{2}{c}{$h=0.8 \mathrm{~m}$} & \multicolumn{2}{c}{$h=1.0 \mathrm{~m}$} \\
& Before impact & After impact & Before impact & After impact & Before impact & After impact & Before impact & After impact \\
\hline I & 1.673 & 1.833 & 1.688 & 1.910 & 1.699 & 1.956 & 1.675 & 1.990 \\
II & 1.685 & 1.819 & 1.703 & 1.862 & 1.683 & 1.919 & 1.708 & 1.916 \\
III & 1.661 & 1.814 & 1.670 & 1.853 & 1.671 & 1.850 & 1.672 & 1.855 \\
Average & $\mathbf{1 . 6 7 3}$ & $\mathbf{1 . 8 2 2}$ & $\mathbf{1 . 6 8 7}$ & $\mathbf{1 . 8 7 5}$ & $\mathbf{1 . 6 8 4}$ & $\mathbf{1 . 9 0 8}$ & $\mathbf{1 . 6 8 5}$ & $\mathbf{1 . 9 2 0}$ \\
\hline
\end{tabular}

content results are shown in Table 4, where the label sequence indicates that sample locations proceeded from shallow to deep.

Table 4 shows that the water content after impact decreased, which was mainly attributed to two causes: (1) the water in the soils migrated and discharged along the cracks caused by impact loading; and (2) the pore water pressure in compacted soils became negative, resulting in increased matrix suction and the improvement of soil strength, which further reduced the water content.

3.1.2. Variation of Soil Density. Under impact loading, pores in soils were compacted, increasing the density. For each impact loading (or drop height), the soils below the impacted holes were sequentially sampled from shallow to deep, labeled as 1,2, and 3, respectively, as shown in Table 5. The measured densities before and after the impact loading are listed in Table 5 as well.

The densities at different depths were essentially the same before impacting. After impacting, the density increased by 7.7-9.5\%, and for each impact energy, the density of the soil sample nearer to the impact point increased further. This is because the upper soils were directly contacted by the drop hammer, absorbing more impact energy and resulting in higher compaction. The impact energy decreased along the depth, and, thus, the lower soils could absorb less impact energy, resulting in less compaction and less variation in the density. In addition, Table 5 shows that the larger impact energy (corresponding to a greater drop height) caused more significant variation of soil density.

3.1.3. Variation of Void Ratios and Saturation. Pore structures significantly affect the mechanical behavior of unsaturated soils subjected to impact loading. However, it was difficult to measure the variation in pore structures during the impact tests. Therefore, the variation of the void ratio before and after impact loading was utilized to reflect the effects of the void ratio and the saturation on the matrix suction.

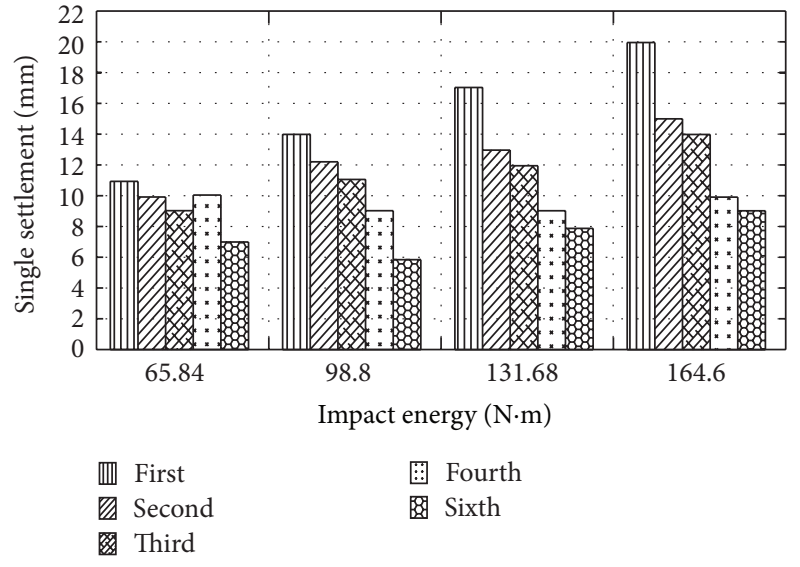

FIgURE 3: Relationship of impacted hole depth with impact energy.

The permeability of soil reflects its capability of mitigating and discharging water, thus indicating the capability of changing matrix suction due to environmental variation. In addition, the permeability of unsaturated soils depends on saturation. Table 6 shows that, with increasing impact energy, the soil saturation gradually increased. For example, under the impact energy of $164.60 \mathrm{~N} \cdot \mathrm{m}$ (corresponding to the drop height of $1.0 \mathrm{~m}$ ), the saturation of the tested soils increased by approximately $30 \%$, leading to a great change in the permeability and further matrix suction. A greater impact energy also caused a larger change in the void ratio. As a result, the impact loading significantly affects the matrix suction.

3.2. Variation of the Impacted Hole Depth under Impact Loading. Figure 3 shows the impacted hole depth due to each impact energy. Under each impact energy, the soil settlement due to each impact was unequal, and the first impact always caused the largest soil settlement. Moreover, the greater the energy of each impact was, the larger the settlement was. 
TABLE 6: Void ratios and saturation of soils below the impacted holes.

\begin{tabular}{|c|c|c|c|c|c|c|}
\hline \multirow{2}{*}{ Drop height $h / \mathrm{m}$} & \multicolumn{2}{|c|}{ Average water content } & \multicolumn{2}{|c|}{ Void ratio } & \multicolumn{2}{|c|}{ Saturation } \\
\hline & Before impact & After impact & Before impact & After impact & Before impact & After impact \\
\hline 0.4 & $19.87 \%$ & $18.52 \%$ & 0.935 & 0.756 & $57.41 \%$ & $66.11 \%$ \\
\hline 0.6 & $19.79 \%$ & $18.44 \%$ & 0.917 & 0.706 & $58.26 \%$ & $70.57 \%$ \\
\hline 0.8 & $19.58 \%$ & $18.39 \%$ & 0.917 & 0.675 & $57.63 \%$ & $73.52 \%$ \\
\hline 1.0 & $19.61 \%$ & $18.43 \%$ & 0.917 & 0.665 & $57.76 \%$ & $74.78 \%$ \\
\hline
\end{tabular}

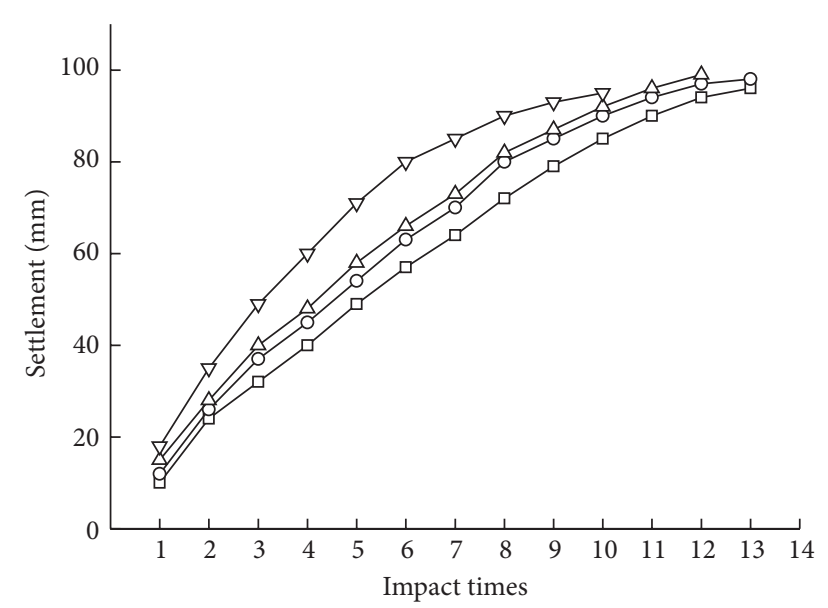

$\begin{array}{ll}\text { Hammer drop height } & \\ -\square-H=0.4 \mathrm{~m} & -\triangle H=0.8 \mathrm{~m} \\ -\bigcirc-H=0.6 \mathrm{~m} & \rightarrow-H=1.0 \mathrm{~m}\end{array}$

FIGURE 4: Relationship of soil settlement with the number of impact loading.

For each impact energy, the settlement of every impact gradually decreased with increasing number of impacts. For the last several impacts, the settlement tended to be the same, indicating that the soil had already been fully compacted.

The relationships of the settlement to the number of impact loading for each given drop height are shown in Figure 4 . The settlement of the first impact was always the largest, and in the ensuing several impacts, the settlement had an approximately linear relationship with the impact number. With increasing impact number, the effect on the settlement became marginal. The analysis based on nonlinear regression shows that the depth of the impacted holes was approximately a quadratic function of the impact number, with a correlation coefficient of 0.9989-0.9995.

Although the settlement due to each impact was unequal for each set of tests under a given impact energy, the eventual total settlement of each set of tests was nearly the same, converging to a critical value. However, to reach this critical settlement, the larger the impact energy was, the lower the required impact number was. Therefore, in engineering practice of dynamic consolidation, it is necessary to combine different impact energies and optimize the combination for the most economic solutions.

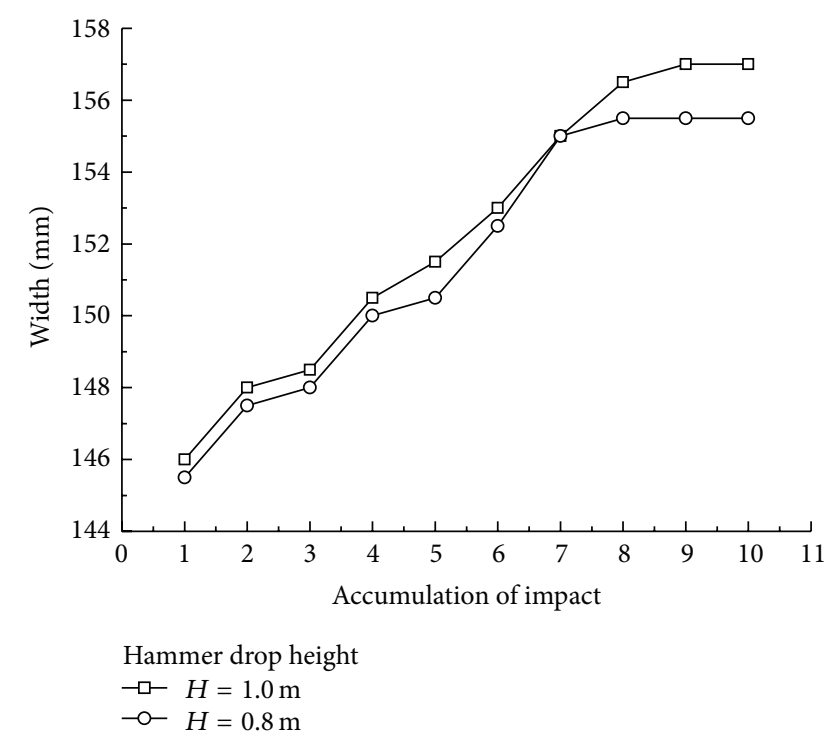

FIgURE 5: Relationship of impacted hole width with the number of impact loading.

3.3. Variation of Impacted Hole Width under Impact Loading. The impact force caused by the drop hammer induced vibrations of the particles around the hammer. These vibrations spread outward in waves. Consequently, the impacted hole width increased with increasing impact loading number.

The relationship of the impacted hole width to the number of impact loading was demonstrated for drop height of $0.8 \mathrm{~m}$ and $1.0 \mathrm{~m}$, as shown in Figure 5. The diameter of the hammer was $135 \mathrm{~mm}$, and under the first impact, the impacted hole width was $10 \mathrm{~mm}$ larger than the hammer diameter. This reflected the stress wave propagation and the energy transfer. For drop heights of $0.8 \mathrm{~m}$ and $1.0 \mathrm{~m}$, the impact energies were $131.68 \mathrm{~N} \cdot \mathrm{m}$ and $164.60 \mathrm{~N} \cdot \mathrm{m}$, respectively, but they resulted in almost the same impacted hole width. Because the horizontal dynamic stress affected a very limited region and the energy dissipated quickly, the impact energy had a much lower effect on the impacted hole width than on the depth. Moreover, with increasing impact number, the hole width slowly increased and eventually remained unchanged. The shape of the impacted holes was similar to a semiellipse. This was probably because when impacted, the soil was compacted, and the pore gas was squeezed out around the hammer edge, which, in turn, pushed the soil at 


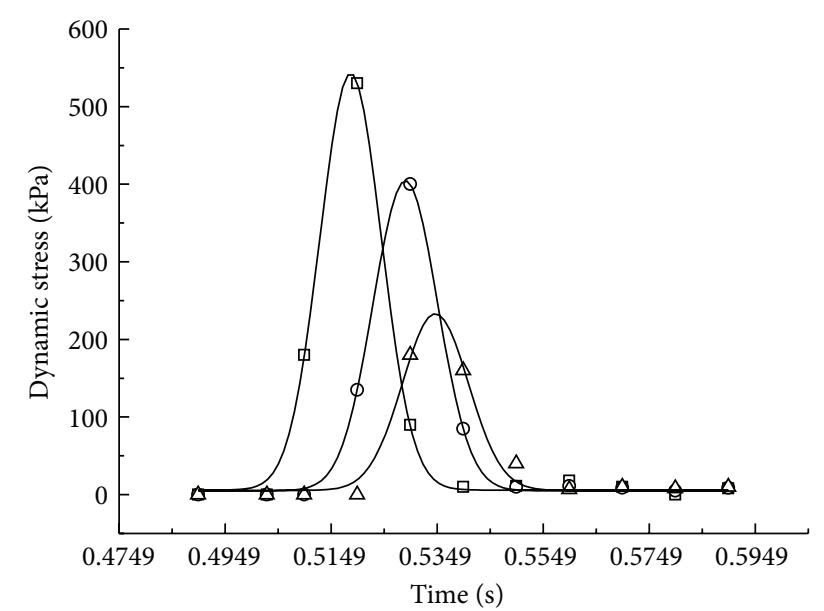

Sequence of impact

口 Tenth impact

o Sixth impact

$\triangle$ First impact

FIgURE 6: Time history of stress waves under sequence of impact.

the interface of the hammer and the hole inward. However, the pores inside the unsaturated soils were discontinuous, and the cross section of impacted hole showed an ellipse shape rather than an idealized circle.

3.4. Variation of Stress in Unsaturated Soils under Impact Loading. To investigate the effect of the impact energy on the dynamic stress, a series of earth pressure boxes were mounted at depths of $10 \mathrm{~cm}, 20 \mathrm{~cm}, 30 \mathrm{~cm}, 40 \mathrm{~cm}, 50 \mathrm{~cm}, 55 \mathrm{~cm}, 60 \mathrm{~cm}$, and $65 \mathrm{~cm}$, below the impacted surface. Figure 6 shows the stress wave signals measured $10 \mathrm{~cm}$ below the impact surface for the first, sixth, and tenth impact, a drop height of $0.8 \mathrm{~m}$. When the impact started, the stress increased sharply from zero to a peak value and then plunged down to zero. The duration time of the induced stress was approximately 0.03 to $0.04 \mathrm{~s}$.

Under impact loading, the pore gas and water of the soil were gradually squeezed out, and the pores were diminished. Then the soil particles moved, and the soil structures changed. The compacted soil could more easily propagate the stress wave, and thus the peak value of the measured stress increased under the later impact. For instance, the peak stress under the tenth impact was two times greater than that under the first impact.

Figure 7 shows the distribution of peak stress along the depth measured by a series of earth pressure boxes under each impact. It can be seen that the peak stress decayed very quickly along the depth near the impact surface. From a depth of $10 \mathrm{~cm}$ to a depth of $20 \mathrm{~cm}$, the magnitude of peak stress decreased by $75 \%$. Consequently, the dynamic stress could affect only a region confined to a depth of $45 \mathrm{~cm}$. The soils between the impact surface and a depth of $20 \mathrm{~cm}$ were the most intensively affected by impact loading. The corresponding pore water and gas were redistributed, and many interfaces formed. When the stress wave passed

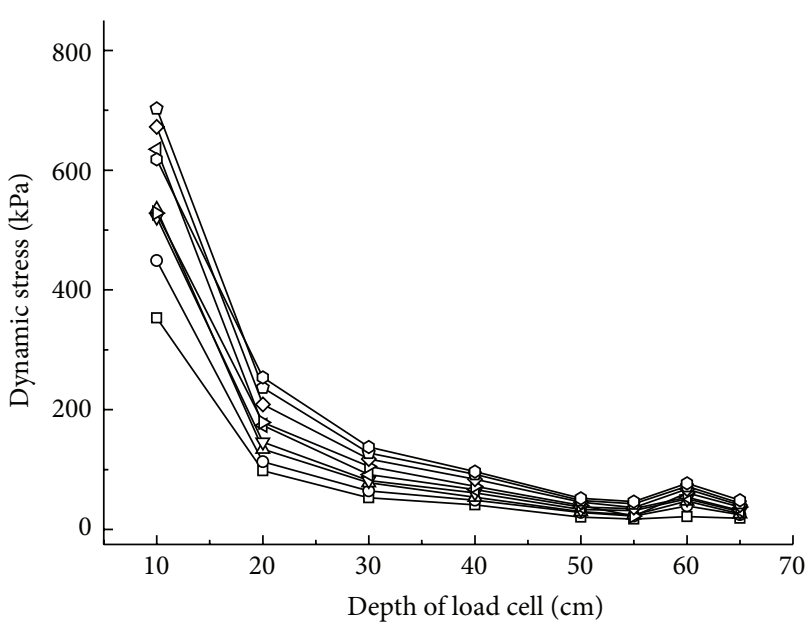

$$
\begin{array}{ll}
\text { Impact numbers } & \\
\neg-N=1 & \rightarrow N=6 \\
\multimap-N=2 & \multimap-N=7 \\
\neg-N=3 & \multimap-N=8 \\
\neg-N=4 & \multimap-N=9 \\
\neg-N=5 &
\end{array}
$$

FIgURE 7: Variation of peak dynamic stress with depth.

through the interfaces, many waves were reflected, and the transmission wave became much smaller than the incipient wave and was unable to disturb the deeper soil. Figure 7 also demonstrates that, under the initial several impacts, the peak stress was still small; however by increasing the number of impacts, the peak stress at each depth increased and eventually tended to converge to a constant, indicating that the soil had already been fully compacted.

The relationships of the peak dynamic stresses measured at different depths to the impact energy under the first and the second impact are shown in Figures 8(a) and 8(b), respectively. It can be seen that the relationships at the first two impacts are very similar, and the dynamic stress at the shallower layer (such as at a depth of $0.1 \mathrm{~m}$ ) was much more sensitive to the increased impact energy. The effect of the impact energy on the dynamic stress decreased with increasing depth. As a result, in the engineering practice of dynamic consolidation, it is necessary to optimize the combination of the impact energy and the effective reinforcement depth of soils.

3.5. Conclusions. In this paper, the mechanical behavior of unsaturated soils was investigated by comparing soil properties before and after impact loading and varying the impacted hole dimensions under different impact energies. The experimental investigations led to the following conclusions:

(1) Prior to impact loading, the unsaturated soil samples had loose structures, high water contents, small densities, large void ratios, and low saturation. However, after the impact loading, the soil structures were changed, and the soil particles were redistributed, leading to relatively lower water contents, smaller void ratios, and higher saturation. The density of the 


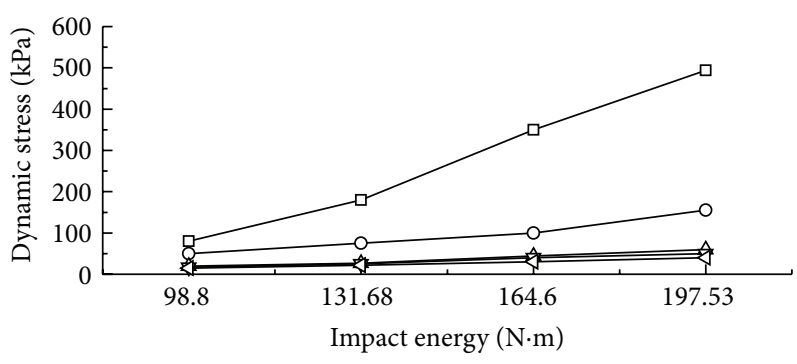

$\begin{array}{ll}\text { Measurement points depth } & \\ \neg-H=0.1 \mathrm{~m} & -\checkmark-H=0.4 \mathrm{~m} \\ \multimap-H=0.2 \mathrm{~m} & -\neg H=0.5 \mathrm{~m} \\ -\triangle H=0.3 \mathrm{~m} & \end{array}$

(a)

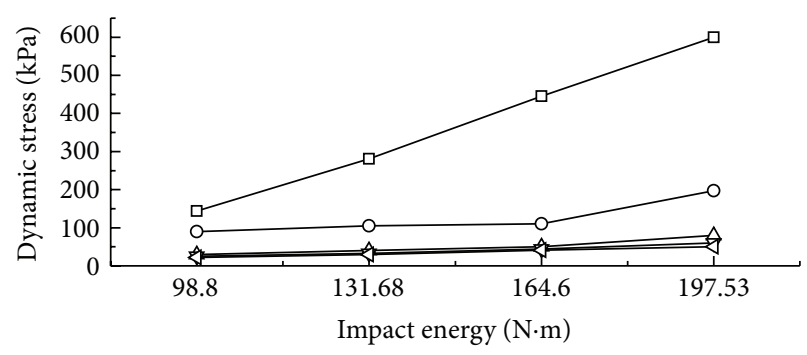

$$
\begin{array}{ll}
\text { Measurement points depth } & \\
\neg-H=0.1 \mathrm{~m} & -\nabla-H=0.4 \mathrm{~m} \\
\multimap-H=0.2 \mathrm{~m} & \checkmark-H=0.5 \mathrm{~m} \\
-\triangle H=0.3 \mathrm{~m} &
\end{array}
$$

(b)

FIGURE 8: Relationship of peak dynamic stress to impact energy: (a) first impact, (b) second impact.

soils near the impact point increased more than that in the other regions. These variations in soil properties affected the matrix suction of the unsaturated soils.

(2) For soils subjected to the same impact energy, the settlement of impacted soils due to each impact was unequal, and the contribution of each impact on the settlement became marginal with increasing number of impact loading. Conversely, the impacted depth increased with increasing impact energy and eventually came to a critical value by increasing the number of impact loading.

(3) The impact loading has little effect on the impacted hole width. The hole width due to the first impact was greater than the diameter of the drop hammer. The horizontal dynamic stress decayed quickly and thus affected a very limited region. Therefore, increasing impact energy fails to enlarge the impacted hole width. Moreover, the impacted hole shape was semielliptical, and the hole perimeter increased with depth.

(4) The effect of impact loading on soil properties decreased with depth. The vertical dynamic stress mainly affected the shallow region, and the stress near the impact point decayed fastest. The dynamic stress increased with increasing impact loading number, but the marginal increment decreased and eventually converged to a constant. As a result, in the engineering practice of dynamic consolidation, it is necessary to optimize the combination of the impact energy and the effective reinforcement depth of soils.

\section{Conflict of Interests}

The authors declare that there is no conflict of interests regarding the publication of this paper.

\section{References}

[1] S. H. Luo, Y. W. Wang, J. Y. Yang, and T. F. Deng, "The statistical laws of surficial deformation of loess ground during dynamic compaction," Advanced Materials Research, vol. 250-253, pp. 1602-1611, 2011.

[2] S.-J. Feng, K. Tan, W.-H. Shui, and Y. Zhang, "Densification of desert sands by high energy dynamic compaction," Engineering Geology, vol. 157, pp. 48-54, 2013.

[3] A. N. Dancygier and Y. S. Karinski, "A simple model to assess the effect of soil shear resistance on the response of soil-buried structures under dynamic loads," Engineering Structures, vol. 21, no. 12, pp. 1055-1065, 1999.

[4] J. Li and D. W. Ding, "Nonlinear elastic behavior of fiberreinforced soil under cyclic loading," Soil Dynamics and Earthquake Engineering, vol. 22, no. 9, pp. 977-983, 2002.

[5] M. Koike, T. Kaji, P. Usaborisut, T. Takigawa, A. Yoda, and S. Takahashi, "Several contributions to soil compactibility induced by cyclic loading test," Journal of Terramechanics, vol. 39, no. 3, pp. 127-141, 2002.

[6] M. M. Sadeghi and F. H. Beigi, "Dynamic behavior of reinforced clayey sand under cyclic loading," Geotextiles and Geomembranes, vol. 42, no. 5, pp. 564-572, 2014.

[7] S. D. Naranjo, C. Sandu, S. Taheri, and S. Taheri, "Experimental testing of an off-road instrumented tire on soft soil," Journal of Terramechanics, vol. 56, pp. 119-137, 2014.

[8] J. H. Hwang and T. Y. Tu, "Ground vibration due to dynamic compaction," Soil Dynamics and Earthquake Engineering, vol. 26, no. 5, pp. 337-346, 2006.

[9] R. L. Kushwaha, V. S. Shankhla, and D. S. D. Stilling, "Soil stress distribution related to neutralizing antipersonnel landmines from human locomotion and impact mechanisms," Journal of Terramechanics, vol. 40, no. 4, pp. 271-283, 2003.

[10] J. Krümmelbein, S. Peth, and R. Horn, "Determination of precompression stress of a variously grazed steppe soil under static and cyclic loading," Soil and Tillage Research, vol. 99, no. 2, pp. 139-148, 2008.

[11] M. Omidvar, M. Iskander, and S. Bless, "Response of granular media to rapid penetration," International Journal of Impact Engineering, vol. 66, pp. 60-82, 2014.

[12] H. Brandel and H. Matsuoka, "Dynamic stresses in soil caused by falling weights," in Proceedings of the 9th International Conference on Soil Mechanics and Foundation Engineering, vol. 2, pp. 187-194, Tokyo, Japan, July 1977.

[13] Z. Niu, G. Lu, and D. Cheng, "Dynamic characteristics of soils subject to impact loadings," Acta Mechanica Solida Sinica, vol. 21, no. 4, pp. 347-353, 2008. 
[14] R. L. Holloman, V. Deshpande, and H. N. G. Wadley, "Impulse transfer during sand impact with a solid block," International Journal of Impact Engineering, vol. 76, pp. 98-117, 2015.

[15] Ministry of Construction of the People's Republic of China, Code for Design of Building Foundation, Ministry of Construction of the People's Republic of China, 2002. 


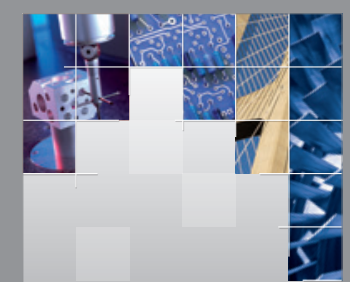

\section{Enfincering}
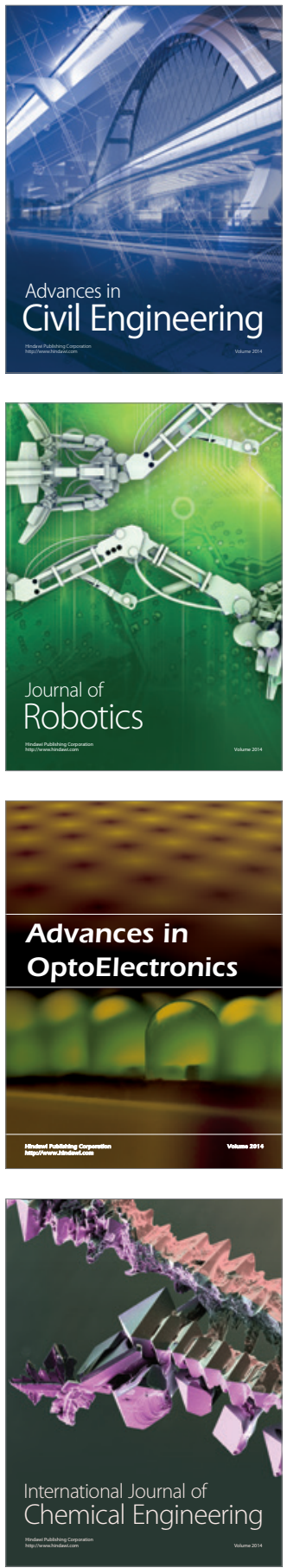

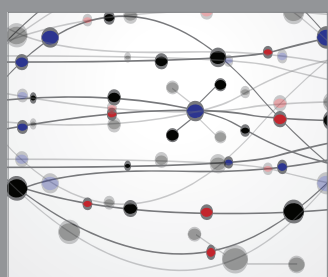

The Scientific World Journal

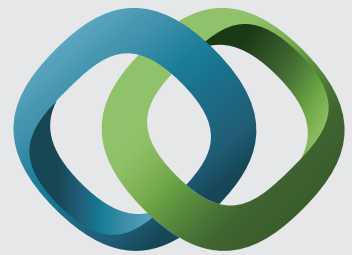

\section{Hindawi}

Submit your manuscripts at

http://www.hindawi.com
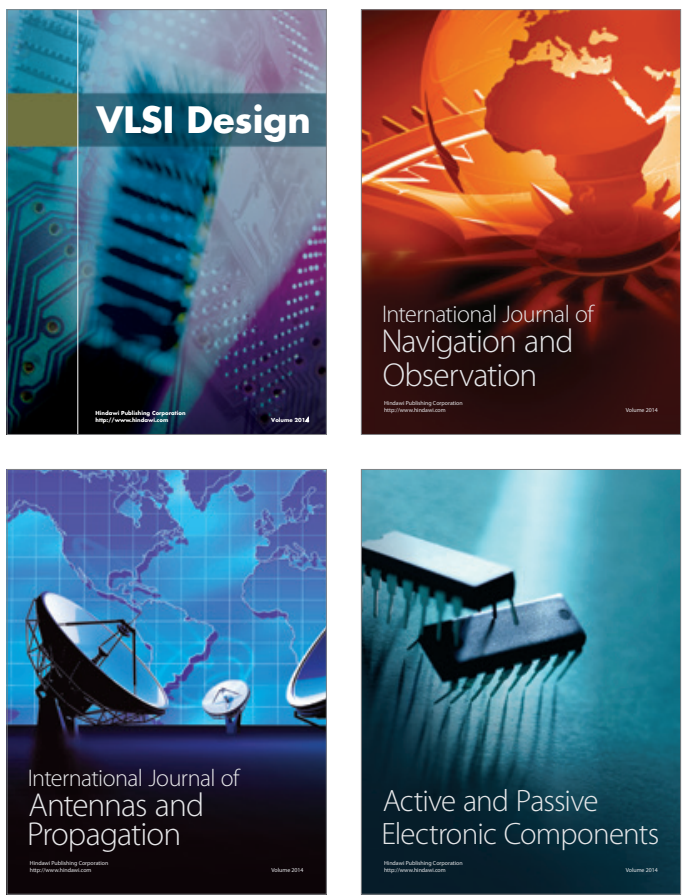
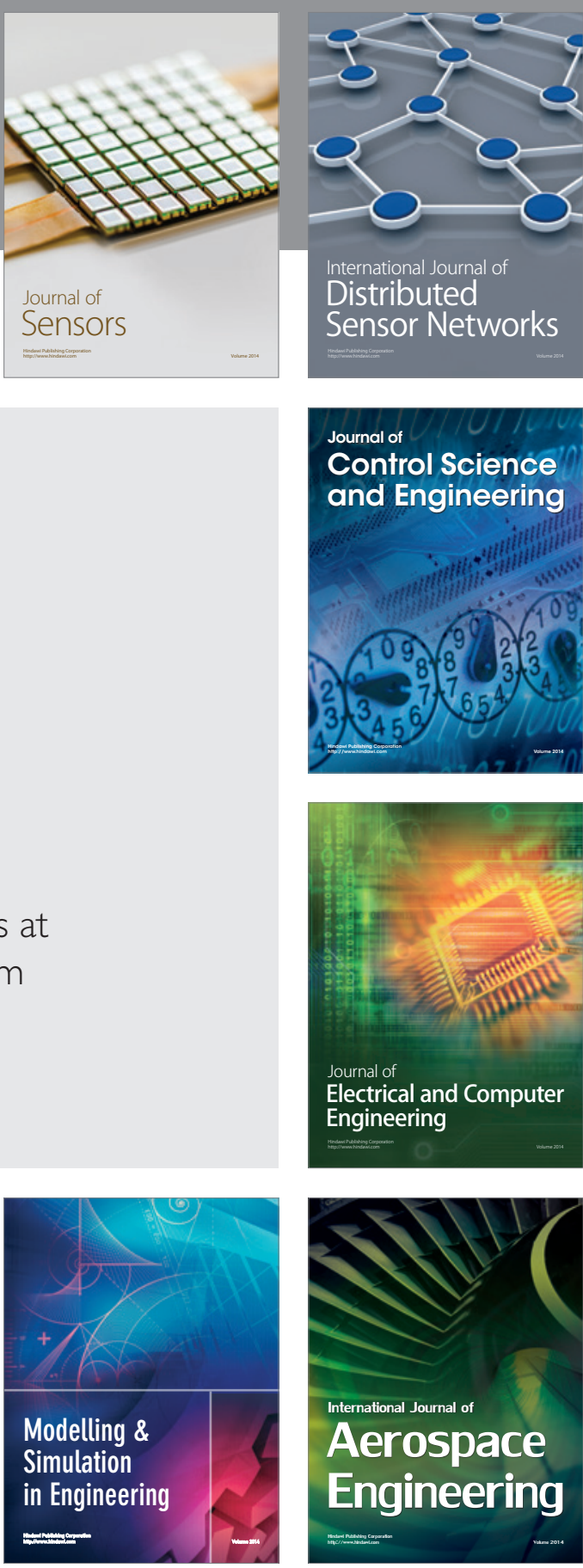

International Journal of

Distributed

Sensor Networks

Journal of

Control Science

and Engineering
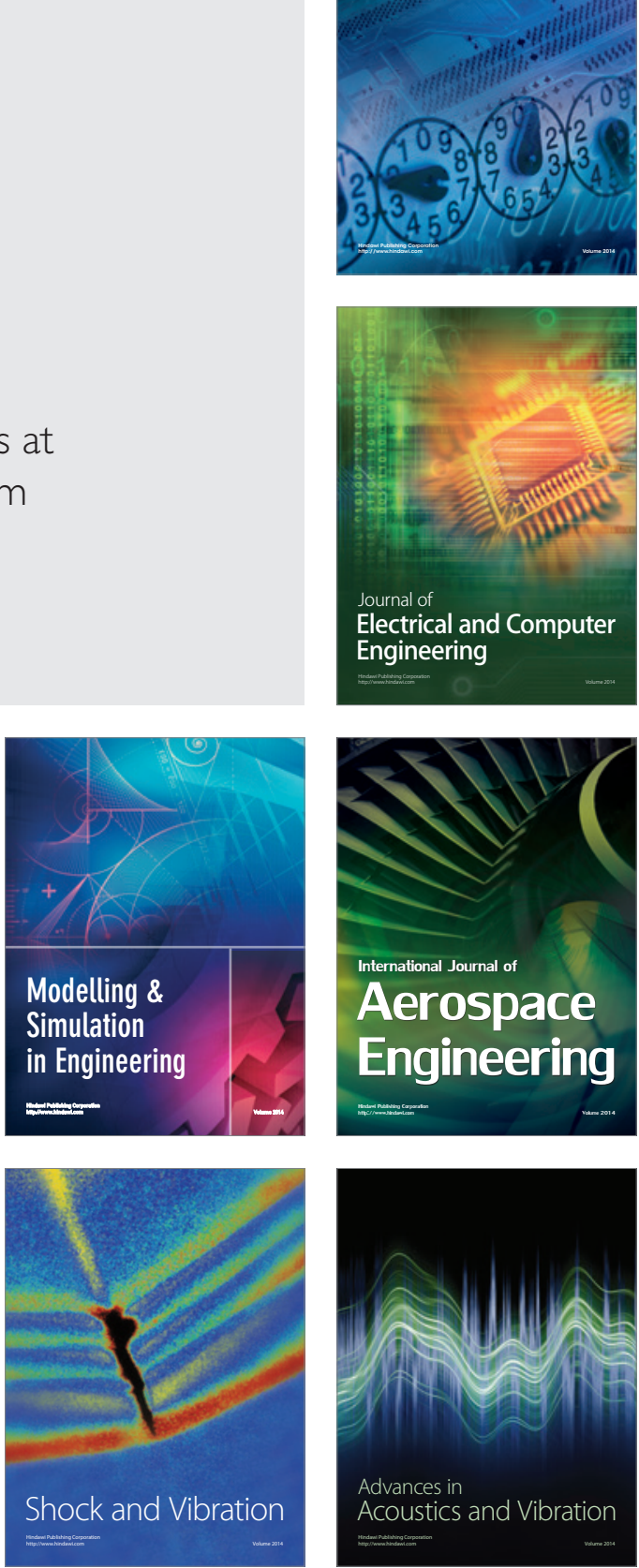